\title{
Converting scanned images for display in human experimental research on IBM or IBM-compatible computers
}

\author{
MICHAEL J. HAUTUS and MARGARET A. FRANCIS \\ University of Auckland, Auckland, New Zealand
}

\begin{abstract}
A program for the conversion of TIFF files of scanned images for display on IBM PCs is described. The program allows line drawings from various sources to be displayed in Turbo Pascal programs. The resultant picture files can be converted on a range of monitors, and the images displayed in different colors.
\end{abstract}

The digitization of pictures for psychological experiments is often time-consuming, and the results relatively unsatisfactory. The use of a mouse or graphics tablet is laborious and inefficient. With the advent of scanners, pictorial stimuli such as line drawings can be digitized simply and effectively. We have written a program in Turbo Pascal to convert image files from scanners using the Tag Image File Format (TIFF) so that the images may be displayed in programs written in Turbo Pascal (Versions 4.0 to 5.5). TIFF files are widely used in desk-top publishing packages such as Aldus PageMaker, and they are produced by most PC-based scanners.

Previous authors have converted scanned images for use in experiments on the Macintosh. Brooks (1985) scanned pictures using the New Image Technology digitizer, edited the pictures in Macpaint, and decoded the resultant pictures for display in basic programs on the Macintosh.

\section{Types of Images}

Line drawings from a variety of sources may be scanned and displayed. We have successfully displayed realistic drawings originating from newspapers and books, as well as hand-drawn pictures. Standardized sets of pictures such as those of Snodgrass and Vanderwart (1980) have also been scanned and displayed successfully in experiments. Text and Chinese or Japanese characters are also suitable for scanning and conversion.

Pictures with a sharp contrast work best. Line drawings of any color may be used, but the scanner must be set to monochrome mode in order to produce monochrome TIFF files. When finally displayed, the images can appear in normal video (white on black) or inverse video (black on white), or in whichever background and foreground colors are desired, provided a color graphics display is used. The user can select the appropriate screen

Correspondence should be addressed to Margaret A. Francis, Department of Psychology, University of Auckland, Private Bag, Auckland, New Zealand. resolution (in pixels) before converting the images. The pictures may also be edited in Turbo Pascal.

Figure 1 represents a picture and text scanned from a newspaper advertisement. Figure 2 represents a picture scanned from a book. The images were captured from a converter program, using the Grab.Com utility provided with WordPerfect 5.0, and printed in WordPerfect. The printed picture and text provide a very accurate representation of the appearance of converted images on a VGA display in high-resolution mode.

\section{The Scanning and Conversion Process}

The TIFF files must be converted to Turbo Pascal files on a computer with the same video adapter as that on the machine on which the pictures will be displayed. The

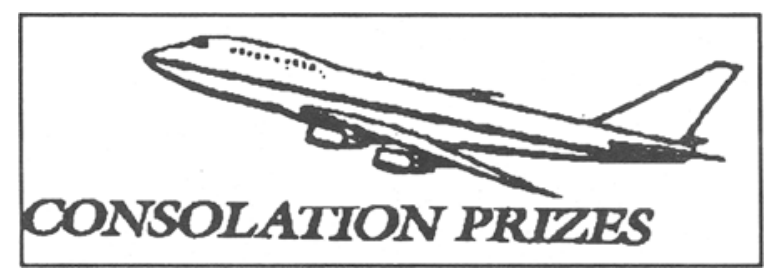

Figure 1. The appearance of a scanned picture and text on a VGA display after conversion $(640 \times 480$ pixels mode).

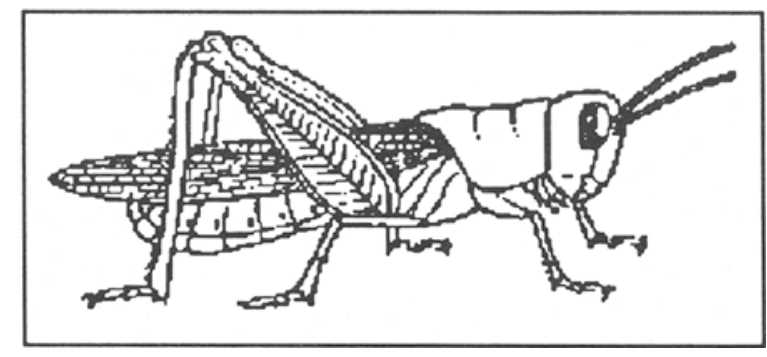

Figure 2. A typical scanned and converted image from a VGA display $(640 \times 480$ pixels mode). 
TIFF file converter decodes uncompressed files, displays the image, and then saves the image from the screen in Turbo Pascal. The images can be successfully presented with Hercules Monochrome, CGA, EGA, MCGA, and VGA adapters. A VGA display's $640 \times 480$-pixel resolution produces crisp images.

The TIFF converter program samples information contained in the TIFF file to construct the image. The higher the resolution of the graphics system, the greater the amount of original information that is used to construct the image. Hence the final picture file is smaller than the corresponding TIFF file. In the case of MCGA and Hercules Monochrome adapters in high-resolution mode, the picture files are approximately $25 \%$ of the size of the original TIFF files.

As an example of the scanning process, a HewlettPackard ScanJet was used to scan 52 Snodgrass and Vanderwart (1980) pictures. The Scanning Gallery software supplied by Hewlett-Packard with the ScanJet is typical of most software provided with scanners, is simple to use, and runs within a windows environment. The Scanning Gallery enables the user to place a box around the portion of a page to be scanned and to select the final image size, and to crop (trim) the image. The size of the images may be enlarged up to $400 \%$ or reduced down to $25 \%$ of the original size. The optimal resolution of the images may be selected in terms of image quality and file size.

The scanned images do not require large volumes of disk space. We have found that the 52 image files are sufficiently small to be stored on a $720 \mathrm{~K}$ disk along with subject's data files and analysis and experimental programs. The 52 images can also be loaded into RAM before an experiment is conducted, on a computer with 640K RAM.

The conversion of scanned pictures into Pascal images for display provides an alternative to tachistoscopic presentation in most cases. Interval timing routines with millisecond accuracy have been written in Turbo Pascal (Brysbaert, Bovens, d'Ydewalle, \& Van Calster, 1989; Heathcote, 1988). Provided that the video retrace synchronization procedures (to reduce the variability of display duration) recommended by Heathcote are used with an interval timing routine, pictures may be briefly and accurately presented.

\section{Availability}

A disk containing the TIFF converter, a demonstration program, and advice on using the converter and scanning procedures is available for $\$ 30$ US. Specify whether a 5.25-in. floppy or 3.5-in. 720K disk is required. Requests should be sent to Margaret A. Francis, Department of Psychology, University of Auckland, Private Bag, Auckland, New Zealand.

\section{REFERENCES}

Brooks, J. O., III. (1985). Pictorial stimuli for the Apple Macintosh computer. Behavior Research Methods, Instruments, \& Computers, 17, 409-410.

Brysbaert, M., Bovens, N., D'Ydewalle, G., \& Van Calster, J. (1989). Turbo Pascal timing routines for the IBM microcomputer family. Behavior Research Methods, Instruments, \& Computers, 21, 73-83.

HEATHCOTE, A. (1988). Screen control and timing routines for the IBM microcomputer family using a high-level language. Behavior Research Methods, Instruments, \& Computers, 20, 289-297.

SNOdGrass, J. G., \& VANDERWART, M. (1980). A standardized set of 260 pictures: Norms for agreement, familiarity and visual complexity. Journal of Experimental Psychology: Human Leaming \& Memory, 6, 174-215.

(Manuscript received November 3, 1989; revision accepted for publication June 15, 1990.) 